\title{
pro.posıções
}

$e$-ISSN 1980-6248

http://dx.doi.org/10.1590/1980-6248- 2021-0065ES

DIVERSO E PROSA

\section{Mitos y realidades sobre el nacimiento de la Pedagogía del Oprimido: una conversación con testigos directos de la escritura de Paulo Freire en Chile 1234}

Myths and realities about the birth of the pedagogy of the oppressed: a conversation with direct witnesses to the writing of Paulo Freire in Chile

(i) Universidade do Estado do Rio de Janeiro - Centro de Educação e Humanidades, Rio de Janeiro, RJ, Brasil. https://orcid.org/0000-0002-2263-9732.wokohan@gmail.com.

(ii) Facultad Latinoamericana de Ciencias Sociales Chile - Educación, Santiago, Chile. https://orcid.org/0000-0001-6102-1380.marcelagajardoj@gmail.com.

(iii) Pennsylvania State University - Penn State College of Education, Pennsylvania, United States. https://orcid.org/0000-0002-2452-5819.jdh91@psu.edu

\footnotetext{
${ }^{1}$ Esse texto da seção "DIVERSO E PROSA" compõe o DOSSIÊ "Paulo Freire e a Educação: cem anos de dialogação, problematização e transformação”, publicado nesta mesma edição.

${ }^{2}$ Editor Responsable: Silvio Donizetti de Oliveira Gallo. https://orcid.org/0000-0003-2221-5160

${ }^{3}$ Normalización bibliográfica: Marina Teles (Tikinet) - revisao@tikinet.com.br

${ }^{4}$ Información de financiación: Conselho Nacional de Desenvolvimento Científico e Tecnológico (CNPq) Processo (307724/2019-0); Programa Institucional de Internacionalização da Coordenação de Aperfeiçoamento de Pessoal de Nível Superior (CAPES-PrInt): Processo (88887.311740/2018-00); Programa Cientista do Nosso Estado da Fundação de Amparo à Pesquisa do Estado do Rio de Janeiro (CNE-Faperj): Processo E26/202.771/2018.
} 


\title{
pro.posições \\ $e$-ISSN 1980-6248
}

http://dx.doi.org/10.1590/1980-6248- 2021-0065ES

\begin{abstract}
Resumen
Esta entrevista con dos figuras extranjeras, una de ellas asistente de Paulo Freire en sus años en Chile, busca aclarar algunos aspectos relacionados con la traducción y la primera circulación de la Pedagogía del Oprimido. Son también analizadas las semejanzas y diferencias entre las diversas traducciones diferentes del libro al castellano y algunas circunstancias de la traducción al inglés del libro. Son también abordados en la entrevista otros aspectos como la génesis del concepto de "acción cultural", una polémico sobre la "concientización", el contexto político de los círculos en los que trabajó Freire en Chile y su influencia en la Educación en Estados Unidos
\end{abstract}

Palabras clave: Pedagogía del Oprimido, Paulo Freire, acción cultural, concientización

\begin{abstract}
This interview with two international figures, one of them Paulo Freire's assistant during his years in Chile, seeks to clarify some aspects related to the translation and first circulation of Pedagogy of the Oppressed. The similarities and differences between the different translations of the book into Spanish and some circumstances of the translation into English of the book are also analyzed. Other aspects addressed in the interview are the genesis of the concept of "cultural action", a controversy about "conscientization", the political context of the circles in which Freire worked in Chile and his influence on Education in the United States.

Keywords: Pedagogy of the Oppressed, Paulo Freire, cultural action, awareness
\end{abstract}

Esta conversación tuvo lugar entre los meses de febrero y marzo de 2021 por correo electrónico. Marcela Gajardo me había enviado (a Walter Kohan) su libro Paulo Freire: Crónica de sus Años en Chile (Flacso, 2019). Me impresionó mucho y percibí cómo su testimonio directo es fundamental para conocer mejor los años de Paulo Freire en Chile, decisivos para su pensamiento y vida posterior. Muy amablemente aceptó que conversáramos más detallada y detenidamente sobre algunas cuestiones suscitadas en su libro e invitó a la conversación a John Holst, su amigo personal y un eximio estudioso de esos mismos años. Además, John Holst es un fluente hablante y escritor de la lengua castellana, por lo que esta conversación tuvo lugar en este idioma. Agradezco la generosidad, paciencia y amistad que ambos entregaron en los meses que conversamos. 


\section{pro.posıções \\ $e$-ISSN 1980-6248}

Walter Kohan: Estimada Marcela Gajardo, hay muchos mitos y versiones sobre la escritura de la Pedagogía del Oprimido y sus primeras ediciones. ¿Podrías contarnos de la “cocina” del libro, de esos años en Chile en que acompañaste a Paulo Freire en el Instituto de Capacitación e Investigación en Reforma Agraria (ICIRA) en Santiago ese tiempo en que él estaba escribiendo el manuscrito del libro?

Marcela Gajardo: Es a partir de 1967 y, sobre todo, en 1968, que Paulo comienza los borradores ("rascunhos", pues escribía en portugués) de la Pedagogía del Oprimido, que termina publicándose en 1970, en inglés primero por Herder \& Herder (después Continuum y más recientemente Bloomsbury) y en español por Tierra Nueva (en Montevideo) después. Las dos son editoriales de inspiración cristiana y formaban parte de las redes de sectores progresistas de la iglesia católica, pero, sobre todo, de instituciones de las iglesias protestantes, como ISAL (Junta Latinoamericana de Iglesia y Sociedad), integrada por miembros de iglesias protestantes residentes en Argentina, Brasil, Chile, Uruguay, México y Venezuela ${ }^{5}$.

Antes, estos textos habían sido debatidos y comentados por todos aquellos a quienes Paulo agradece en la introducción, además de otros profesionales y participantes de los cursos y actividades del ICIRA. No considero que valga la pena discutir si la versión mecanografiada que publicó el PIIE antecedió o no la versión manuscrita que publicó el Instituto Paulo Freire con la editorial Nove de Julho en la edición conmemorativa de los 50 años de la Pedagogía del Oprimido. Lo cierto es que la versión que Paulo regaló a Jacques Chonchol fue la que él entregó, también a fin de mecanografiar, tanto a los norteamericanos (para traducir) como a los chilenos (para dactilografiar y traducir).

Lo que sí puedo asegurar, porque yo los organicé, es que los textos que forman parte de los capítulos II e III de la Pedagogía del Oprimido son versiones revisadas de los documentos que publicó ICIRA bajo el título de Sobre la Acción Cultural. Fueron divulgados ampliamente estos textos por ISAL, como documentos de circulación interna, mucho antes que saliera la publicación de ICIRA. En dos ediciones de la revista Cristianismo y Sociedad del ISAL se divulgaron muchos de los textos que, años después, se publicaron en español y portugués. Recuerdo vívidamente una tarde en que Paulo entró

\footnotetext{
${ }^{5}$ Para esta y otras cuestiones tocantes al protestantismo en esos años, véase Brugaletta (2017). Y para una visión más amplia de la recepción de la Pedagogía del Oprimido en América Latina, véase la tesis doctoral de Brugaletta (2020).
} 


\section{pro-posıções \\ $e$-ISSN 1980-6248}

http://dx.doi.org/10.1590/1980-6248- 2021-0065ES

a mi cubículo con un manojo de papeles en manos y me dijo, "por favor, lee estos materiales, organízalos por tema y escribe una introducción explicando su origen y propósito”. A eso me dediqué gran parte del 1968 tratando que la versión final reflejara los debates internos del equipo de ICIRA. Carlos Ruiz Tagle, editor en jefe de ICIRA, iba leyendo los borradores y editando el portuñol. Sostenía, en ese tiempo, que Paulo no debía escribir sino "grabar" sus libros, anticipándose varios años a las conversaciones publicadas por Paulo en asociación con distintos autores en sus libros "hablados".

Walter Kohan: ¿Puedes decirnos algo acerca del concepto de "acción cultural” y el libro publicado sobre él?

Marcela Gajardo: Claro. El libro Sobre la Acción Cultural (concepto acuñado en esa época y perfeccionado más tarde por los profesionales del IDAC (Instituto de Acción Cultural), en Ginebra) salió casi junto con la Pedagogía del Oprimido, pero en Chile tuvo tal impacto que se reimprimió tres veces. La primera versión es de 1969, y la tercera, de 1972. Eran los años de la Unidad Popular en Chile y teníamos nuestra propia debacle política. En el año 1973 estábamos a las puertas del golpe. El equipo de ICIRA se había dispersado y la atención internacional la concentraban los nuevos equipos que Paulo integró en Ginebra y que fueron claves en la adaptación de conceptos y métodos para contextos y actores diversos, sobre todo africanos y europeos. Rosiska y Miguel Darcy de Oliveira fueron, a mi juicio, claves en apoyar a Paulo conceptual y metodológicamente. Claudius Ceccon hizo su parte en la ilustración de ideas y conceptos usando para ello la caricatura política. El equipo de IDAC retornó a Brasil casi junto con Paulo. Prontamente se vincularon con la jerarquía de la iglesia paulista y sus movimientos sociales. Ellos permanecen muy reservados siempre acerca de su rol en las acciones que realizaron juntamente con Paulo, sobre todo en los países africanos. Como en Chile, Paulo escribía y ellos actuaban. Gran parte de lo que hicieron está contenido en las publicaciones del IDAC y se puede reconstruirlas. No considero que para los fines de comprender cómo fue la cocina de la Pedagogía del Oprimido valga la pena meterse en estas honduras. Para eso, mejor quedarse en los escritos tempranos y las publicaciones en el tiempo que Freire pasó en Harvard para cerrar de una vez por todas el tema de si es más válida una versión manuscrita que otra de Pedagogía del Oprimido. Más bien, aventurar algunas hipótesis del porqué del vuelco de Freire desde la política, nuevamente a la pedagogía. Mi impresión es que ello se debe a que, a su regreso a Brasil, en el 1980, él fue contratado como 


\section{pro-posıções \\ $e$-ISSN 1980-6248}

http://dx.doi.org/10.1590/1980-6248-2021-0065ES

académico y profesor en la Universidad Católica de São Paulo (PUC-SP) y en la Universidad Estadual de Campinas (UNICAMP) e invitado frecuente por otras universidades nacionales y extranjeras. Más tarde, se fue desencantando paulatinamente con la política contingente, especialmente después de sus años como secretario de educación de la ciudad de São Paulo. Fiel a sus principios, sin embargo, nunca dejó de militar en el PT [Partido de los Trabajadores], lo que lo alejó de varios de sus colegas del exilio en Chile, como Almino Affonso y Fernando H. Cardoso.

Para cerrar este capítulo, hay un vacío de información sobre el que podemos trabajar porque hay escritos publicados en inglés en revistas de Harvard y está la traducción al inglés y francés de otros documentos que también sirvieron para redactar Pedagogía del Oprimido. Mi parecer es lo que Paulo realizó en los Estados Unidos, además de los seminarios que ofreció en Harvard, fue seguir trabajando sus tesis educativas con base en la clarificación conceptual de su teoría de la acción cultural que vino a reemplazar los clásicos y anacrónicos conceptos de alfabetización y educación de adultos tal como los venía conceptualizando la UNESCO. Lo otro que hizo Paulo en Harvard fue revisar la traducción de Pedagogía del Oprimido al inglés con Myra Berman Ramos ${ }^{6}$.

Walter Kohan: ¿Qué puedes decirnos de su producción editorial en Harvard?

Marcela Gajardo: Paulo se quejaba mucho, en ese tiempo, de las exigencias que le imponían sus editores. En ese periodo en Harvard conoció a Noel McGinn que describe muy bien la llegada de Freire a Cambridge donde a él le tocó recibirlo. Las publicaciones de su autoría en Harvard son Cultural Action for Freedom, publicado por Harvard Educational Review y el Center for the Study of Development and Social Change en septiembre de 1970. Está prologado por João da Veiga Coutinho, que era el profesor que gestionó su invitación al Center for the Study of Development and Social Change. En las notas sobre el autor dice textualmente:

\footnotetext{
${ }^{6}$ Para quien tenga interés en conocer más sobre la traductora y su relación con la obra, se ha publicado recientemente una entrevista en la que, por ejemplo, declara que Pedagogía del Oprimido fue su primer y único trabajo de traducción. Veáse Loivos (2020).
} 


\title{
pro.posıções \\ $e$-ISSN 1980-6248
}

http://dx.doi.org/10.1590/1980-6248- 2021-0065ES

\begin{abstract}
Paulo Freire, until recently a Fellow of the Center for Studies in Education and Development, is now serving as a consultant to the Office of Education at the World Council of Churches in Geneva, Switzerland. In Chile, he served as consultant to Unesco's Institute of Research and Training in Agrarian Reform (ICIRA). Prior to that, in Brazil, he was Secretary of Education and General Coordinator of the National Plan for Adult Literacy. His most recent book, entitled Pedagogy of the Oppressed, will be published in October 1970 by Herder and Herder. (Tengo el texto físico que me regaló Paulo cuando lo visité en Ginebra en diciembre de 1970)
\end{abstract}

Walter Kohan: Marcela Gajardo y John Holst, ¿qué nos pueden ayudar a elucidar sobre la orientación política de los círculos académicos y no académicos con los que trabajaba Freire, en especial en Chile, pero también en Harvard?

Marcela Gajardo: En esos años, Paulo tuvo una influencia significativa sobre académicos norteamericanos, en su mayoría del campo de la educación de adultos. Primero, a través de sus relaciones con Ivan Illich quien lo introdujo a las actividades de las iglesias y movimientos civiles en Norteamérica. Illich le presentó a Eric Fromm con quién se reunió para conversar sobre sus ideas. En cambio, es de la década siguiente, su amistad con académicos e intelectuales como Ira Shor, por ejemplo, o con activistas como Myles Horton, con quien publicó un libro "conversado" (Freire \& Horton, 2018). Por supuesto, con Henry Giroux, el padre norteamericano de la pedagogía crítica. Discutía sus textos en inglés y se integraba a entidades y movimientos que, entonces, recién asomaban al escenario latinoamericano. Pero, una salvedad: todos o en su gran mayoría eran entidades y movimientos de inspiración cristiana. De hecho, en Chile, las ideologías y partidos de izquierda, sobre todo los ortodoxos, no adscribían ni al pensamiento ni a las prácticas freireanas. Para ellos solo valía “el viejo Marx”. Así me lo hizo saber Iván Nuñez, socialista, que en la época de Allende fue el número tres en la estructura del Ministerio de Educación nacional y autor intelectual de la política educativa de la Unidad Popular. Paulo también tenía cercanía intelectual con los jesuitas chilenos y ofreció cursos y conferencias en el Instituto de Educación Rural y en ILADES (Instituto Latinoamericano de Doctrina y Estudios Sociales). Patricio Cariola, fundador y director del Centro de Investigación y Desarrollo de la Educación (CIDE), jesuita, de orientación demócrata cristiana, visitaba con frecuencia a Freire para conocer de cerca lo que estaba haciendo en los campos de la alfabetización y capacitación campesina. Varios estudios del CIDE se inspiraron en las investigaciones participativas que promovía Paulo: estudios cualitativos, de percepciones, desarrollo comunitario, etc. Otras congregaciones 


\section{pro.posıções \\ e-ISSN 1980-6248}

http://dx.doi.org/10.1590/1980-6248- 2021-0065ES

de católicos también frecuentaban los cursos de ICIRA. Al nivel regional, con ocasión de la Conferencia Episcopal de Medellín se relacionó muy de cerca con Cecilio de Lora y otros. Ya en el Consejo Mundial de Iglesias su cercanía con católicos progresistas y protestantes ecuménicos era un hecho. INODEP por ejemplo hizo un detallado análisis de los textos producidos en ICIRA y publicó, por la editorial Marsiega, un libro que se titula El mensaje de Paulo Freire. Y otro, titulado Concientización reúne mucho de lo que Paulo hizo en Chile y en Brasil. (La sede del INODEP estaba en una congregación de monjas francesas y sus redes eran todos católicos y protestantes europeos). John Holst, que es norteamericano, puede decirnos algo más sobre el tiempo en Harvard, sobre lo que ya ha escrito. Quizás le sirva a John Holst el prólogo que João da Veiga Coutinho escribió para Cultural Action for Freedom. En una parte dice "in the voice of Paulo Freire the Third World still disdains to address itself to the managers of the First. In his opinion, and in that of many of his peers, there can be no dialogue between antagonists. But Freire invites the hitherto silent sectors of the affluent world or at least the more awakened members of those overmanaged, overconsuming societies to a rediscovery of the world in which they live and of their own vocation in that world, in dialogue with its pariahs. That his invitation did not fall on deaf ears was demonstrated by the enthusiastic response of students and other minorities to his brief passage in this country last year. The Center for the Study of Development and Social Change—was convinced that an encounter of Paulo Freire with the American reality, and of the actors in the struggling grass-roots movements with his thought and personality, could only have salutary effects. It was not mistaken”. (Preface, p. V)

John Holst: Freire llega a la universidad de Harvard, ubicada en la ciudad de Cambridge, Massachusetts, a fines de abril o a principios de mayo del año 1969. Sabemos que estuvo en Cambridge en mayo por una carta que Freire le escribe a su sobrina Nathercia Lacerda (2016), quien la publica en un libro muy lindo de recuerdos y con otras cartas que ella habia recibido de su tío Paulo durante el exilio de éste. En el libro de Nathercia hay una carta del 12 de octubre de 1969 escrita por Paulo Freire desde Cambridge, Massachusetts, en la cual el mismo Freire dice lo siguiente: “Como você talvez já saiba, desde maio passado estamos morando em Cambridge. Vamos ficar aqui até o próximo fevereiro, quando então iremos para Genebra, por três anos" (p. 68). Estas fechas también coinciden con las investigaciones que hizo Gottesman (2016) en los archivos 


\section{pro.posıções \\ $e$-ISSN 1980-6248}

http://dx.doi.org/10.1590/1980-6248-2021-0065ES

de la Universidad de Harvard. Gottesman encontró el contrato de Paulo Freire con Harvard, el que iba del $1^{\circ}$ de septiembre de 1969 hasta el 28 de febrero de 1970. Así es que Freire llega a Cambridge en mayo de 1969, aunque oficialmente no empieza a trabajar en Harvard hasta septiembre. Sabemos que Freire estuvo en el centro CIDOC de Ivan Illich en el verano (norte) de 1969, donde participa en un seminario con Eric Fromm y otros intelectuales. Por el testimonio de McFadden (2010), sabemos que Freire vuelve a Cambridge para pasar allí el mes de agosto de 1969. El testimonio de McFadden es interesante porque dice que Freire aceptó su pedido de tutoría informal durante el mes de agosto de 1969 en Cambridge. En su primera sesión de tutoría, Freire le pasa Sobre la Contradicción y Sobre la Práctica, de Mao Tse-Tung, como lectura, y una fotocopia del manuscrito de Pedagogía del Oprimido en portugués al fin de la primera semana de tutoría. Lo de Mao es interesante porque, en un texto que Freire escribe para un seminario en IDAC en enero de 1970, cita bastante a este autor sobre el concepto “contradicción”. Además, McFadden nos presenta evidencias de la llegada de Freire a Estados Unidos con fotocopias del manuscrito original de Pedagogía del Oprimido, el mismo que también les había dejado a Jacques Chonchol y Maria Edy en 1969 en Santiago.

Walter Kohan: John Holst, ¿qué influencia tuvo Freire en la educación de Estados Unidos en esa época?

John Holst: Una conclusión que Gottesman saca de sus investigaciones sobre la influencia de Freire en los estudios de educación de los Estados Unidos de los años setenta es que fuecasi nula. Dice que no es hasta los años ochenta, y con el apoyo de Henry Giroux, que la obra de Freire empieza a tener un impacto en los estudios de la educación estadounidense. Esta conclusión corresponde a lo que Giroux mismo dice sobre sus colaboraciones con Freire y Donaldo Macedo, que empiezan con el encuentro de los tres en la casa de Giroux en 1981, la que resulta ser la primera vez que se encuentran Giroux, Macedo y Freire en persona . Como educador de adultos y alguien que ha trabajado en el campo de la pedagogía crítica, estoy de acuerdo y en desacuerdo con Gottesman. Tiene razón en términos de la recepción de la obra de Freire en los estudios de Educación, pero solo si nos limitamos a la escolarización o la educación de niños y jóvenes como estudios de la Educación. Lo que pasa es que quienes reciben a Freire en Cambridge, en su mayoría, son académicos, profesionales, y activistas que trabajaban en 


\section{pro.posıções \\ $e$-ISSN 1980-6248}

http://dx.doi.org/10.1590/1980-6248- 2021-0065ES

la educación de adultos y en la educación no formal y comunitaria. Como la educación de adultos no es el enfoque de la investigación de Gottesman, no capta esta recepción temprana de Freire en los Estados Unidos. Por ejemplo, el trabajo docente que Freire hace en Harvard es un curso que ofrece con David Harman el semestre de otoño (norte). Harman, en esa época, es un importante académico en el campo de la educación y alfabetización de adultos, y sobre la que escribe varios libros (Harman, 1974; Hunter \& Harman, 1979).

Walter Kohan: Muy interesante, John Holst, ese panorama que nos das sobre la época de Paulo Freire en Cambridge, es bastante poco conocido entre nosotros. Sé también que has estudiado la recepción de las primeras versiones de la Pedagogía del Oprimido. ¿Podrías decirnos a qué conclusiones llegaste en ese sentido?

John Holst: Primero, Gottesman estudió las primeras reseñas de Pedagogía del Oprimido que se publican en los Estados Unidos en los primeros años de la década de los setenta, y algunas, no todas, eran bastantes negativas. También debo resaltar que en mi campo de la educación de adultos, donde la obra de Freire fue más conocida y discutida en esos años, llama la atención que Freire presente lo que Grabowski (1972) llama un "dilema revolucionario" para los educadores de adultos. Ese "dilema", en mi opinión, tiene que ver en primer lugar con la idea de una pedagogía para el oprimido, o sea, por el hecho de hablar tan directamente, tan abiertamente, de la existencia de opresores y oprimidos en el campo de la educación, y también por el contenido del capítulo cuatro de Pedagogía del Oprimido. Y pensando en ese "dilema" interesa considerar lo siguiente: a través de mi más reciente lectura de Pedagogía de la Esperanza, me di cuenta de que, para Freire, Pedagogía del Oprimido iba a ser un libro de tres capítulos. Él dice en Pedagogía de la Esperanza que después de dejar el manuscrito en su escritorio por dos meses, y después de leer el prefacio que Ernani Maria Fiori ya había escrito basado en su propia lectura de los tres capítulos que Paulo le había entregado, Freire se dio cuenta de que hacía falta otro capítulo; que era un manuscrito incompleto. De allí es d dónde sale la idea del capítulo cuarto que, en mi opinión, es distinto de los primeros tres capítulos. Sobre todo, ideológicamente, para mí, es el más "radical” o, por lo menos, el más obviamente radical; es allí donde habla de la relación entre el líder revolucionario y las masas, entre otros aspectos. También es donde habla sobre acción cultural. Sería procedente, entonces, contrastar la visión de acción cultural que aparece en el capítulo 


\section{pro.posıções \\ $e$-ISSN 1980-6248}

http://dx.doi.org/10.1590/1980-6248- 2021-0065ES

cuatro con la que aparece en los capítulos dos y tres. Otro punto de interés para mí es el hecho de que el prefacio de Ernani María Fiori está basado en una lectura de Pedagogía del Oprimido con tres capítulos, no cuatro. Es decir, es un prefacio para “otro" libro o, al menos, para una versión primera y menor del libro.

Marcela Gajardo: Creo que descubrimos el misterio del capítulo cuatro de Pedagogía del Oprimido. El tema de las vanguardias y las masas, los temas y antitemas son todos parte de los debates que teníamos en ICIRA con la lingüista Martine Hughes, quien sostenía que no podían existir las codificaciones "neutras" porque la función de una codificación era desafiar a los sujetos a interpelar la realidad observada. Martine tenía una muy sólida formación en universidades francesas y fue un gran aporte al ICIRA. Insistía en que una imagen problematizadora, a fin de alcanzar su objetivo pedagógico - esto es, desafiar, problematizar-, no puede y no debe constituir una simple reproducción de la realidad... Una imagen de esa naturaleza lejos de devolver a los educandos su situación como problema ocasiona, en general, una respuesta ligada a la pseudoverdad de un ser sumergido en un mundo que oculta la verdad. Tanto Paulo como Ernani Maria Fiori reaccionaron frente a esto. Fiori (1991) dijo “... el método de Paulo Freire no absorbe lo político en lo pedagógico ni enemista la educación con la política” (p. 20). Freire, a su vez, nos señalaba en un escrito inédito: "uno de los puntos débiles de mi trabajo, en mis primeros trabajos teóricos no hice ninguna o casi ninguna referencia al carácter político de la educación y descuidé el problema de las clases sociales y su lucha. Dejé la puerta abierta a todo tipo de interpretaciones, ..." En escritos posteriores, Freire plantea la necesidad de una "vanguardia" o "partido" capaz de organizar y liderar a las masas, pero, como señalan Rosiska Darcy de Oliveira y Pierre Dominici, desde el exilio en Ginebra, fiel a su rechazo de toda manipulación y transposición del saber, advierte que las relaciones entre partido y clases oprimidas no pueden ser una relación entre polo portador de una "conciencia" histórica y otro portador de una "conciencia vacía"7.

Considero que mucho del IV capítulo de Pedagogía del Oprimido está en esta dirección y puede encontrarse en dos documentos: el informe final de actividades de Freire a la

\footnotetext{
${ }^{7}$ El artículo de Rosiska Darcy de Oliveira y Pierre Dominici está publicado en Cuadernos de Pedagogía de Barcelona en un dossier dedicado a Freire e Illich en el año 1974. Entre las páginas 4 y 16 y se titula "Freire/Illich Pedagogía del Oprimido. Opresión de la Pedagogía. El debate pedagógico”.
} 


\section{pro.posıções \\ $e$-ISSN 1980-6248}

Unesco que está en los Anexos de mi libro Freire. Crónica de sus años en Chile (Santiago: FLACSO, 2019) y en los documentos publicados en la Harvard Educational Review como Cultural Action for Freedom (otoño del 1969) ${ }^{8}$ y en un documento titulado La Educación de los Adultos como Acción Cultural. Proceso de la Acción Cultural. Introducción a su comprensión. La versión en inglés es la que publicó Harvard, pero la versión en español fue objeto de discusión en un seminario organizado por Adveniat y la Comunidad Latinoamericana de Roma. Fue en abril de 1970, y la versión en español fue publicada en agosto de 1970. Es muy parecido al texto que John Holst nos compartió en francés (Freire, 1970) de lo que yo deduzco que Freire salió primero a Harvard y después fue a Roma y ese texto fue traducido del español al inglés. Comparé las versiones y tiene mucho del último informe al que me referí.

Walter Kohan: John Holst, ¿puedes decirnos algo sobre el "misterio" del manuscrito original de Pedagogía del Oprimido y sobre las diferentes versiones del libro que estarían circulando en diferentes lenguas?

John Holst: El propio Freire entregó el manuscrito al agrónomo chileno Jacques Chonchol y a su esposa brasileña Maria Edy Ferreira como regalo de despedida en 1969, cuando Freire parte de Chile a Harvard. No era de hecho un misterio para los chilenos que trabajaron con Freire durante cuatro años y medio en Chile (1964-1969); sabían que Jacques y Maria Edy tenían el manuscrito original y lo habían llevado consigo a su exilio en París; Paulo también nos dice en Pedagogía de la Esperanza que hizo transcribir ese manuscrito y que esas copias fueron las que se usaron como base para las traducciones al inglés y al castellano.

De modo que la idea de que existen versiones muy variadas de Pedagogía del Oprimido, al menos en español e inglés, en comparación con el manuscrito original simplemente no es verdad. Muy poco o nada se pierde al leer cualquiera de estas versiones en comparación con las otras. Salvo ligeras modificaciones y elecciones de palabras del traductor, se está leyendo el mismo texto. Incluso la versión reciente en castellano

\footnotetext{
${ }^{8}$ En una sección de Anexos Bibliográficos se reseña Cultural Action for Freedom como publicado por Penguin (Londres, 1972) y se define su contenido como "explicitación y desarrollo de las características y condiciones del proceso de concientización, presente en todos sus trabajos anteriores, y definido ahí como "acción cultural para la libertad". Y, entre lo poco que había en ese tiempo hay un Curso de Autor2 (París, INODEP, ciclostil). Marcela Gajardo nos dijo que Paulo la mandó a hacer esto después de una reunión en Chantilly en tiempos en que Marcela Gajardo hacía su postgrado en Inglaterra.
} 


\section{pro.posições \\ $e$-ISSN 1980-6248}

http://dx.doi.org/10.1590/1980-6248-2021-0065ES

publicada por UTEM en Santiago no es significativamente diferente de la que circula hace tantos años publicada por Siglo XXI. Es cierto que esta última versión es un poco más apegada al original en portugués. En mi opinión ha llegado el momento de dejar de lado cualquier preocupación sobre "una" versión auténtica de Pedagogía del Oprimido. Eso no significa que el libro en diferentes idiomas y culturas no haya dado lugar a muchas interpretaciones y "muchos Freires" como ha sostenido recientemente Sandro Barros (2020).

Walter Kohan: John Holst, ¿`uáles son en tu consideración las principales diferencias entre la edición en castellano traducida por Jorge Mellado conjuntamente con José Luis Fiori y Marcela Gajardo publicada primero en Tierra Nueva y después en Siglo XXI y la que se ha publicado recientemente por UTEM en Santiago de Chile?

John Holst: En comparación con la edición española de Tierra Nueva de 1970, la nueva traducción al castellano de la UTEM es más fiel o cercana a una versión anterior al manuscrito portugués. Lo mismo ocurre si comparamos esta edición con la traducción al inglés; aunque, es mucho más fácil traducir estrechamente del portugués al castellano que del portugués al inglés. Sin embargo, esta fidelidad al original no hace necesariamente que la edición de la UTEM sea una mejor traducción, al menos por dos razones. En primer lugar, hay una serie de errores muy desafortunados en la traducción de la UTEM que socavan el evidente cuidado que se puso en el diseño de lo que es una hermosa edición de Pedagogía del Oprimido. Como punto positivo, en el texto de la UTEM se proporciona una traducción de la carta de Freire a Jacques Chonchol y Maria Edy que él les entregó junto con el manuscrito. Esto es muy beneficioso para los lectores de lengua española y no aparece en otras versiones de Pedagogía del Oprimido, en castellano o en inglés. Lamentablemente, en la carta, "años" se traduce erróneamente como "meses", por lo que la carta se lee como si hubieran pasado cuatro meses desde que Freire hubiera llegado a Chile y no cuatro años. Como la carta está firmada en la primavera de 1968, los lectores, como Luis Pinto Faverio, presidente de la Universidad Técnica Metropolitana, cuyo prefacio está incluido en el texto, podrían cometer el error que él comete, y pensar que Freire llegó a Chile en 1968 y no en 1964, como fue el caso. En segundo lugar, hay algunas elecciones de traducción más desafortunadas y pobres que no se encuentran en la traducción original al español de Jorge Mellado en colaboración con Marcela Gajardo y José Luis Fiori. Es evidente que Mellado, Marcela Gajardo y José 


\section{pro.posıções \\ $e$-ISSN 1980-6248}

http://dx.doi.org/10.1590/1980-6248-2021-0065ES

Luis, que trabajaban con Freire en ICIRA cuando él escribía Pedagogía del Oprimido en Chile, no hubieren hecho estos errores de traducción porque fueron participantes directos con Freire en el desarrollo del texto y su aplicación en la práctica con los trabajadores de la reforma agraria.

Walter Kohan: De modo que, en tu consideración, John Holst, los lectores de las distintas traducciones de Pedagogía del Oprimido, incluso comparando con la edición en portugués, no encuentran un texto muy diferente, ¿verdad?

John Holst: Es cierto, para mí las traducciones del portugués al castellano y al inglés no son tan diferentes como para que cambien el sentido del libro en su totalidad. Hay diferencias, pero considero que no cambian fundamentalmente la obra. Además, se nota que los traductores estaban trabajando con el mismo texto o manuscrito.

Walter Kohan: Marcela Gajardo, ¿quieres contarnos tu propia experiencia en la traducción de la Pedagogía del Oprimido?

Marcela Gajardo: La versión publicada por Tierra Nueva en 1970 fue traducida y editada por José Luis Fiori y por mí y, posteriormente revisada y editada por Jorge Mellado, que era el traductor oficial de Freire en ICIRA. Fue el propio Paulo quien nos recomendó a la editora para elaborar la traducción que fuimos haciendo sobre los borradores del manuscrito en portugués. Como pueden imaginar, la "traducción", en consulta con Paulo, dejó bastante que desear. De ahí que recurrieran a Jorge Mellado para revisar el borrador. Es por eso que, en la primera edición de Tierra Nueva (1970), dice: "Edición a cargo de Marcela Gajardo y José Luis Fiori”. Debajo: “Traducción de Jorge Mellado, ICIRA (1968)". La Editorial Tierra Nueva nos pagó por estos trabajos que todos hicimos a título personal. Es probable que, entre los tres, le hiciéramos sugerencias y cortes al texto, pero siempre con la anuencia de Paulo. En la versión con la que nosotros trabajamos solo estaban los agradecimientos a Elza y a los colegas brasileños, todos del ICIRA. También participó Silvia Peirano que era la secretaria del Departamento de Capacitación y dactilografiaba todos nuestros manuscritos. Después, Paulo fue agregando otros nombres a los agradecimientos y, desde Ginebra, nos mandó el párrafo en que nos agradece a José Luis y a mí. No fue fácil para nosotros incorporar este párrafo, ya que, en cuanto asistentes y amigos de Paulo, considerábamos que todo lo que hacíamos con él y para él era un deber de amistad. En ese sentido, encontré muy 


\section{pro.posıções \\ $e$-ISSN 1980-6248}

http://dx.doi.org/10.1590/1980-6248-2021-0065ES

elegante que Tierra Nueva nos reconociera el trabajo editorial y diera el crédito de la traducción a Jorge Mellado. Jorge y yo también trabajamos juntos en la edición de los textos que componen el libro Sobre la Acción Cultural. Paulo usó el informe preliminar de la investigación temática a propósito del tema generador y el universo temático para escribir el último capítulo de la Pedagogía del Oprimido. Por eso en la página 27 bajo el título "Primeras Palabras" escribió 'Las páginas que aparecen a continuación y que proponemos como una introducción a la Pedagogía del Oprimido son el resultado de nuestras observaciones en estos tres años de exilio... . Hasta llegar a los agradecimientos (p. 33) e iniciar con el Capítulo I. Lo que incorpora como Capítulo IV, como matrices de teorías de la Acción Cultural, es resultado del discurso campesino en la Investigación de la Temática Cultural de los Campesinos de "El Recurso", el documento inédito más conocido del mundo, gracias al ISAL, y su réplica de la metodología en barriadas populares -equivalente al informe inédito de Ferreira y Fiori sobre Investigación temática y replicado en Colombia (Cleba y Viejo Caldas).

Walter Kohan: A partir de lo que nos has compartido, ¿qué evaluación haces de las ideas políticas de Paulo Freire y su relación con el campesinado chileno en esos años que estuvo en Chile? A la vez, la salida de Paulo Freire de Chile se debió a un contexto político ya no tan favorable, ¿verdad? ¿Podrías aclararnos estas cuestiones?

Marcela Gajardo: En el 1968, la "agudización de las contradicciones del modelo desarrollista”, como acostumbrábamos a decir, estaba en su punto más alto. Esto se reflejaba en nuestras discusiones de equipo. Paulo "enganchaba" con las posiciones más radicales como corresponde a todo intelectual de izquierda que se precie de tal. A nosotros nos protegía el "escudo" de Freire, pero cuando empezaron los primeros rumores sobre la participación de Freire en política, también nosotros fuimos despedidos por la dirección de ICIRA. ICIRA era un proyecto del gobierno de Chile y de las Naciones Unidas. Por eso no podía comercializar sus publicaciones y solo las usaba con fines de formación e iniciativas privadas con fines públicos. Así pues Paulo pudo ser contratado como consultor UNESCO tal como Almino Affonso era consultor de la OIT [Organización Internacional del Trabajo]. Como funcionarios internacionales, además, debían abstenerse de participar en política o tener injerencia en asuntos nacionales. Ellos respetaron ese compromiso cabalmente. Como el de Paulo, nuestro discurso era en esencia teórico. El movimiento campesino chileno y los sectores urbano-marginales ya 


\section{pro-posıções \\ $e$-ISSN 1980-6248}

http://dx.doi.org/10.1590/1980-6248-2021-0065ES

estaban organizados políticamente y cada uno obedecía a estructuras partidarias distintas. Como académicos e intelectuales, ni Paulo ni su equipo tenía ninguna condición de liderar estos movimientos.

Walter Kohan: Fue justamente en esos años en Chile que Paulo Freire comenzó a usar el tan polémico término concientización, ¿verdad?

Marcela Gajardo: Sí, fue en Chile, en escritos de los equipos de trabajo y en conferencias públicas. Sin embargo, él siempre dijo que el término "concientización" era de autoría de profesionales del ISEB (Instituto Superior de Estudios Brasileros), entre los que estaba Álvaro Viera Pinto. También decía que quien se encargó de divulgar el término había sido don Helder Camara. Para los chilenos, el concepto de la concientización era un neologismo para el cual no existía una definición precisa. Después, leyendo a Viera Pinto, descubrí que, desde un punto de vista pedagógico, la noción remite a un aprendizaje orientado hacia la percepción de realidades económicas, políticas y sociales como requisito indispensable de la acción política y social; desde una perspectiva filosófica, vincula ciencia y existencia, hace consciente la realidad y las contradicciones del mundo humano. Remite, además, a una epistemología donde, de manera ecléctica, se mezclan muchas escuelas de pensamiento filosóficas, sociológicas, psicológicas y pedagógicas. Esta noción, un poco olvidada en la sociología contemporánea, es central en las ideas pedagógicas de Freire y empezó a ser regionalmente conocida como un concepto creado por un equipo de profesores del ISEB hacia el año 1964. El propio Freire nos ayuda a comprender el origen del concepto cuando, participando en un seminario internacional en Roma, señaló en Sobre la Acción Cultural (Santiago: ICIRA, 1972, p. 35) que al oírlo del filósofo Álvaro Viera Pinto y el Prof. Guerreiro Ramos había entendido que, aplicado a la educación, aludía a su potencial creador y crítico.

A partir de las primeras conferencias públicas de Freire, el término "concientización" y el concepto de educación liberadora, propias de los primeros escritos de Freire en Chile? empezaron a ser utilizados para designar aquellas actividades educativas que conllevaban una intencionalidad de cambio. No se trataba de cualquier educación, sino de aquella que buscaba contribuir al cambio de estructuras. El poder y la política empezaron a

${ }_{9}^{9}$ Cfr. Freire (1965), La educación como práctica de la libertad, publicada en español en 1967 por Icira, Santiago, Chile, y en Uruguay por la editorial Tierra Nueva. 


\section{pro.posıções \\ $e$-ISSN 1980-6248}

http://dx.doi.org/10.1590/1980-6248-2021-0065ES

perfilarse como núcleo y motor del trabajo pedagógico. Poco a poco, la especificidad del hecho educativo pasó a ser supeditada a la tarea de desarrollar y fortalecer la capacidad organizativa de aquellos grupos que, en el contexto de sociedades altamente estratificadas, concentradoras y excluyentes, compartían una situación de dominio y pobreza. Hacia fines de los años sesenta, la idea de la concientización y el método que la operacionalizaba habían sido ampliamente difundidos y adoptados en el Sur de las Américas. En Brasil, los programas diseñados y ejecutados como parte de las políticas gubernamentales de desarrollo educativo habían sido abortados con el golpe militar al gobierno nacional desarrollista de João Goulart. El paradigma de la concientización ya no respondía a las intenciones de aquellos grupos y organizaciones que se proponían situar la educación de los sectores populares con miras a lograr un cambio estructural. Al decir de Fals Borda, este modelo se volvió insatisfactorio para todos aquellos que deseaban un trabajo todavía más profundo y radical en la transformación de las sociedades.

Walter Kohan: Y por eso Paulo Freire dejó de usarlo... Pero tal vez haya algo más allí. Decías antes que Paulo era un intelectual más que un político. O sea, claro que tenía compromiso y sentidos políticos, pero también era alguien que le preocupaba mucho pensar y fundamentar teóricamente de forma consistente sus programas y prácticas teóricas. Considero que el concepto de concientización es muy problemático por varias razones. Primero, porque la idea de conciencia supone toda una tradición de pensamiento europeo, racionalista y también dualista; segundo, porque como motor de un proceso educativo, es difícil sostener la idea de concientización en una educación dialógica, democrática, igualitaria: porque si existe una conciencia verdadera, enseñar esa conciencia pasa a tener un valor fundamental y entonces si el campesino ya tiene esa consciencia la educación se vuelve inútil y si no la tiene se puede volver autoritaria e insensible a los saberes del campesinado: además, ¿quién tiene la consciencia verdadera y cómo se sustenta en una educación dialógica en la que nadie educa a nadie, sino que nos educamos los unos a los otros mediados por el mundo? ¿La conciencia estaría en el mundo? En el fondo, la idea de concientización me parece incompatible con una educación que valorice los saberes populares, campesinos, una educación que escuche a la clase oprimida; justamente, un concientizador parece que estaría más preocupado en que se escuche la consciencia a alcanzar que de escuchar. En fin, no sé qué piensan 


\section{pro.posições \\ $e$-ISSN 1980-6248}

http://dx.doi.org/10.1590/1980-6248- 2021-0065ES

ustedes, pero a mí la idea de concientización me parece muy problemática y tal vez Paulo Freire también sintió estas tensiones y tal vez por eso, entre otras cosas, dejó de usar el concepto. ¿Qué les parece? ¿Estoy fantaseando?

Marcela Gajardo: No estás fantaseando. Todos los problemas y contradicciones de esta búsqueda intelectual de Paulo Freire fueron las que explotaron en nuestras caras cuando empezamos a debatir sobre lo que Freire llamaba la "politicidad de la educación" y las relaciones entre poder y educación, entre política y enseñanza. Como él decía, la falta de un referencial teórico sólido abrió las puertas para todo tipo de interpretaciones. Además, como dicen en Brasil, en la práctica la teoría era otra. Empezó a cuestionarse la investigación de los "universos temáticos" a partir de los saberes y percepciones populares. Cobró fuerza el concepto de "saber popular" para aludir a las representaciones con que las organizaciones populares describían y expresaban sus condiciones de vida y de trabajo. La concientización, como concepto, ya no respondía a los propósitos para los que se lo usó originalmente, al menos en Chile. Surgieron tendencias diferentes y posiciones diversas sobre la educación popular, sus fines y funciones. Con la salida de Freire, además, se cerró un ciclo de trabajo del que quedan pocas huellas, ya que una buena cantidad de informes y textos inéditos quedaron sin publicarse. Afortunadamente, hoy jóvenes que están haciendo o han hecho recientemente tesis de doctorado en Brasil, Argentina y Chile están poniendo las cosas en su justo lugar y abriendo espacio a estudios en otras latitudes.

John Holst: Para mí, una de las contribuciones más importantes de Freire está en el campo de la Investigación-acción participativa (IAP). Su insistir en estudiar y leer el mundo real del oprimido con el oprimido como fundamento de cualquier práctica educacional o de formación, para mí, es lo más innovador de Freire. Si a su "método" de alfabetizar le sacamos la investigación previa y participativa tiene muy poco de nuevo. Creo también que con la acción/revolución cultural está tratando de encontrar una manera teórica de sobrepasar las limitaciones de las interpretaciones de la concientización. Digo interpretaciones porque, para mí, su uso no tiene realmente las contradicciones mencionadas, que sí tienen las interpretaciones de otros.

En los estudios de Educación y estudios freireanos en los Estados Unidos, hay muy poco sobre el concepto de acción cultural. Considero que la gente está más cómoda con 


\section{pro.posições \\ $e$-ISSN 1980-6248}

http://dx.doi.org/10.1590/1980-6248-2021-0065ES

la idea de la concientización, aunque es muy difícil entender y pronunciar en inglés (conscientization), y también difícil de entender los niveles de consciencia en obras como Pedagogía del Oprimido y en La Educación como Práctica de la Libertad. Es una lástima que no existan más investigaciones sobre la acción cultural en los estudios freireanos en los Estados Unidos.

La otra gran contribución en mi opinión que Freire hace a los estudios de educación es la dialéctica. En el otro libro todavía no mencionado en esta entrevista que Freire también escribe en Chile, ¿Extensión o Comunicación?, Freire dice que, en la relación educacional o proceso de aprendizaje, “el educador y educando asuman el papel de sujetos cognoscentes, mediatizados por el objeto cognoscible que buscan conocer" (Freire, 1997, p. 28) ${ }^{10}$.

Para mí, es en ese libro donde Freire está combinando su énfasis en la investigación participativa y la relación dialéctica entre personas, con lo que sobrepasa la crítica de que en el proceso de la concientización hay un maestro que sabe y un estudiante que no sabe. La profesora puede mantener su autoridad sin ser autoritaria y estar en una relación de coaprendizaje y de investigación con su par.

Walter Kohan: Muchas gracias, John Holst, es un tema fascinante y podríamos seguir conversando por mucho tiempo. Muchas gracias, Marcela Gajardo, por tu testimonio tan vivo y presente. Recuerdo ahora un apartado de la conversación de Freire con Horton que se intitula "Estoy siempre en el comienzo, como tú" (Freire \& Horton, 1990, p. 55) ${ }^{11}$. Pues eso también me parece ahora, que estamos en el comienzo. Qué bueno terminar esta entrevista con esa sensación de, en el final, estamos comenzando un camino. Tal vez esa sea una de las mayores potencias de la obra -y la vida- de Paulo Freire: llevarnos al comienzo, allí donde está todo por pensar y hacer.

${ }^{10}$ Freire, P. (1997). Antes publicado como Extensión o Comunicación? La concientización en el medio rural (Santiago de Chile: Icira, 1969).

11 Traducción en portugués de 2018 (p. 78). 


\section{pro.posições \\ e-ISSN 1980-6248}

\section{Referencias}

Barros, S. (2020). Paulo Freire in a hall of mirrors. Educational Theory, 70(2), 151-169. https://doi.org/10.1111/edth.12413

Gajardo, M. (2019). Paulo Freire: Crónica de sus años en Chile. Flacso.

Brugaletta, F. (2017). El protestantismo y la circulación de la pedagogía de Paulo Freire en América Latina. Paulo Freire. Revista de Pedagogía Crítica, 15(17), 21-40.

Brugaletta, F. (2020). La edición de Paulo Freire en la bistoria reciente de América Latina [Tesis doctoral, Universidad Nacional de La Plata]. Repositorio Institucional de la UNLP. http://sedici.unlp.edu.ar/handle/10915/99224

Fiori, E. M. (1991). Aprender a decir su palabra: El método de alfabetización del profesor Paulo Freire. In P. Freire, Pedagogía del oprimido. Siglo XXI.

Freire, P. (1997). ¿Extensión o Comunicación? (20a ed.). Siglo XXI.

Freire, P. (1970). La methode d'alphabetisation des adultes. Cuaderno del CIDOC, 9(45), 1-17.

Freire, P., \& Horton, M. (1990). We Make the road by walking. Temple University Press.

Freire, P., \& Horton, M. (2018). O caminho se faz caminhando: Conversas sobre educação e mudança social. Vozes. (Trabajo original publicado en 1990)

Gottesman, I. (2016). The critical turn in education. Routledge.

Grabowski, S. (Ed.). (1972). Paulo Freire: A revolutionary dilemma for the adult educator. Syracuse University Press.

Harman, D. (1974). Community fundamental education. Lexington Books.

Hunter, C. S. J., \& Harman, D. (1979). Adult illiteracy in the United States. McGraw-Hill.

Lacerda, N. (2016). A casa e o mundo lá fora: Cartas de Paulo Freire para Nathercinha. Zit.

Loivos, K. C. (2020). Entrevista com Myra Bergman Ramos. Cadernos de Tradução, 40(2), 365376. https://doi.org/10.5007/2175-7968.2020v40n2p365

McFadden, J. (2010). Paulo Freire memories. In T. Wilson, P. Park, \& A. Colón-Muñiz (Eds.), Memories of Paulo (pp. 15-18). Sense. 


\section{pro.posições \\ $e$-ISSN 1980-6248}

\section{Datos de sumisión}

Sometido a evaluación el 21 de mayo de 2021; acepto para publicación el 03 de julio de 2021.

Autor correspondiente: Universidade do Estado do Rio de Janeiro - Centro de Educação e Humanidades, R. São Francisco Xavier, 524, Sala 12037F, Maracanã, Rio de Janeiro, RJ, Brasil. 